\title{
AC 2010-1394: ENGINEERING MANAGEMENT PERFORMANCE MONITORING METHODS UTILIZED BY MANUFACTURERS TO BECOME MORE COMPETITIVE
}

\section{William Loendorf, Eastern Washington University}

William R. Loendorf is currently an Associate Professor of Engineering \& Design at Eastern Washington University. He obtained his B.Sc. in Engineering Science at the University of Wisconsin - Parkside, M.S. in Electrical Engineering at Colorado State University, M.B.A. at the Lake Forest Graduate School of Management, and Ph.D. in Engineering Management at Walden University. He holds a Professional Engineer license and has 30 years of industrial experience as an Engineer or Engineering Manager at General Motors, Cadnetix, and Motorola. His interests include engineering management, technological literacy, and real-time embedded systems. 


\title{
Engineering Management Performance Monitoring Methods Utilized by Manufacturers to Become More Competitive
}

\begin{abstract}
To become more competitive, organizations have made changes in their operations, manufacturing techniques, and business practices. Innovative technologies are being used, machinery updated, and new strategies followed. Many have also implemented improvement programs to enhance quality, increase efficiency, and streamline operations. However, these actions all come with a cost in terms of capital, personnel, and time. For many small organizations classified as job shops, this may limit their choices to a few actions that must work. However, how is performance monitored and measured? To answer that question a study was conducted in 2008 into one basic type of job shop; the American tool and die shops that fabricate molds, dies, and tools fundamental to the production process. The intent was to understand issues crucial to their existence while they work to improve performance in terms of quality products, satisfied customers, and profits. These are criteria used to judge success for all organizations and as a result, practices from other small businesses may be applicable and transferable to the tooling industry with the reverse also being true. However, each tool shop operates under a unique set of business, cultural, and economic circumstances requiring perhaps a customized solution. Performance monitoring information derived from this study must be incorporated into the management courses associated with the engineering and engineering technology curriculum. The findings indicate that American tool shops are using a variety of methods including change in financial indicators, deliveries, and number of customers. Most tool shops used a monthly timeframe for review and, for the most part, were confident that their measurements were accurate. In order to prepare graduates for manufacturing related engineering and engineering management careers, the results from this study have been directly integrated into multiple engineering and engineering technology courses.
\end{abstract}

\section{Introduction}

The tooling industry has been around for hundreds of years in one form or another. In fact, the industry has been in existence since before the industrial revolution when dies, molds, and other forms of tools were just beginning to be widely used. In those days, a competitor was also a neighbor or the fellow down the street. The competition was from local people and companies.

Due to vast improvements in communication and transportation, competitors are now more likely to be located anywhere in the world. Most likely, they are located in a far away country with little or no environmental regulations, few if any worker rights, lower standard of living, and pay wages that are a small fraction of those paid in America. The situation is even more problematical due to subsidies given by foreign governments to their tooling industries to grow and expand the business. Combining all of these aspects gives foreign tool manufacturers a unique advantage they can exploit against their American counterparts. Manufacturers must reorganize and retool for a global environment $\left(\mathrm{Berg}^{3}, 1998\right)$ in order to be competitive. 
The possible social impact is equally or perhaps even more significant and profound. Individuals, families, and communities suffer when jobs are lost. Lives are disrupted when families are forced to relocate, often to distant locations away from loved ones. Communities and the services they offer are reduced or even eliminated for those left behind. The American way of life, standard of living, and expectation of better lives for the next generation is at stake.

Many tool shops have gone out of business and even more are on the verge. Their loss puts the entire American manufacturing system including the vast military industrial complex in jeopardy. Even our very security as a nation might be at risk. Improving the competitiveness of the American tooling industry is important, but what needs to be improved? How is the ability of manufacturing firms to compete determined? How is their performance monitored, measured and reported? An engineering management study (Loendorf ${ }^{33}$, 2008) into the performance monitoring methods used by the American tooling industry was conducted in 2008 in order to answer these types of questions.

The tooling industry can use the findings to improve performance and efficiency by rethinking the business model and streamlining operations. The intent was to understand issues crucial to their existence while they work to improve performance in terms of quality products, satisfied customers, and profits. These are criteria used to judge success for all organizations and as a result, practices from other small businesses may be applicable and transferable to the tooling industry with the reverse also being true. However, each tool shop operates under a unique set of business, cultural, and economic circumstances requiring perhaps a customized solution.

Engineering students must study, understand, and know how to apply performance monitoring processes and procedures. Critical issues include the methods used to evaluate changes in financial indicators, production, orders, deliveries, number of customers, review timeframe used, and even the accuracy of the data collected. The results from this study have been integrated into multiple engineering and engineering technology courses to prepare students to meet the engineering management challenges offered by manufacturing related engineering positions.

\section{Theoretical or Conceptual Support}

Atkinson $^{1}$ (2000) summarized the rationale behind the use of performance measurement (PM) techniques, "If you can't measure it, you can't manage it" (p. 22). Gregory and Myers ${ }^{23}$ (2002) stated that the objectives of any performance management system were to monitor, identify, and improve the operations and activities of an organization in order to improve profitability. This can be associated with Deming's Plan-Do-Check-Act cycle of continuous improvement (Deming ${ }^{16}, 1982$ ). Industrial performance concerns durability, operational improvements, and the ability to control processes and Berrah, Mauris, and Vernadat ${ }^{6}$ (2004) found that from 1945 to 1975 , purely financial terms were used to judge performance, while after 1975 quality levels and delivery dates were being used.

Bourne $^{8}$ (2005) indicated that the main factor influencing the success or failure of a performance management system was the commitment level of management. Castellan, Young, and Roehm ${ }^{12}$ (2004) uncovered flaws including arbitrary targets and unrealistic expectations that can weaken the organizations ability to utilize performance measures. Wouters and Sportel ${ }^{50}$ (2005) reported 
a strong desire to identify with the existing reports at all levels of the organization; the resistance to change was strong. Castellano and Young ${ }^{11}$ (2006) found that by monitoring and controlling production variations, improvements resulted.

Lockamy $^{32}$ (1998) found that a performance management system (PMS) must align strategy with the market, utilize the organizations resources, and monitor progress toward achieving objectives. Bailey ${ }^{2}$ (2003) argued that organizations could improve their performance monitoring systems by establishing and using key indicators with customer, process, innovative, and financial aspects unique to their organization. Bryant, Jones, and Widener ${ }^{9}$ (2004) discovered a positive correlation between customer satisfaction and financial outcomes. An integrated approach by Medori and Steeple ${ }^{35}$ (2000) included both financial and non-financial measures.

Waggoner, Neely, and Kennerley ${ }^{49}$ (1999) reported that a PMS must include six operational functions: setting objectives, marketing, adherence to specifications, accounting, engineering, and statistical control. Hudson, Smart, and Bourne ${ }^{26}$ (2001) identified requirements for a successful PMS: audits, user involvement, clear objectives, measurement criteria, periodic maintenance, management support, worker support, and setting realistic timeframes. Kaplan and Norton $^{31}$ (1992) developed the balanced scorecard (BSC) approach as a framework for aligning the organizations values, objectives, expectations, and aspirations with customer satisfaction. Kanji $^{29}$ (1998) developed a comparative business scorecard (CBS) that included additional aspects to attain process excellence, advance learning, and achieve profits.

Pun and White ${ }^{44}$ (2005) reviewed both existing and emerging trends in performance measurement systems to discover that no one type of PM system can guarantee success for all organizations. Bento and White ${ }^{5}$ (2001) reported that organizational form (sole proprietorship, partnership, or corporation) was an important aspect tied directly to information costs that had implications on risk management and cost control. Micheli and Kennerley ${ }^{37}$ (2005) suggested a PMS framework for use in both non-profit and for-profit organizations utilizing a flexible methodology tailored to each organizations unique needs and situations. Neely and Al Najjar ${ }^{40}$ (2006) discovered links between employee morale and customer satisfaction that led to improved financial performance.

Riggs $^{46}$ (1983) concluded that a flexible method of measurement was required to capture the many dimensions of organizational performance. Dervitsiotis ${ }^{17}$ (2004) proposed a systematic approach to performance management that viewed the organization as a living entity optimized as a whole. Morgan ${ }^{38}$ (2003) asserted that organizations implement PM systems that reflect management's abilities and beliefs along with those of the workers. Franco-Santos and Bourne ${ }^{18}$ (2005) found that a successful PM system required a commitment from top management, enabled workers, and open communication. Bititci, Turner, and Begemann ${ }^{7}$ (2000) investigated how information technology (IT) systems could perform self-auditing functions using various management tools. Nudurupati and Bititci $^{43}$ (2005) concluded that IT support was able to identify weaknesses, enhance improvement projects, and improve decision-making.

Hudson, Lean, and $\mathrm{Smart}^{25}$ (2001) found that the use of non-financial performance measurement systems was limited in small to medium sized enterprises (SMEs). Garengo, Biazzo, and Bititci ${ }^{20}$ (2005) reported that very few SMEs used performance measurement systems and concluded that 
SMEs needed simple measurement systems. Hvolby and Thorstenson ${ }^{27}$ (2001) found that few SMEs actually utilized formal structured systems to measure their performance and that a focused performance measurement system was required.

Mendibil and MacBryde ${ }^{36}$ (2005) argued that a systematic way to measure the performance of teams was necessary. Lyles, Baird, Orris, and Kuratko ${ }^{34}$ (1993) found major differences between the formal and non-formal planners with the planning process itself actually more important than the resulting plan. Frigo ${ }^{19}$ (2002) determined that a gap existed between developing the organizations strategy and its performance measures.

Gough $^{22}$ (2003) stressed the importance of monitoring and measuring the performance of supplychains. Neely, Mills, Platts, Richards, Gregory, Bourne, and Kennerley ${ }^{41}$ (2000) developed a structured approach for designing performance measurement systems. Tae-Eog and Posner ${ }^{47}$ (1997) studied job shops and concluded that schedules existed for minimizing cycle time for repetitive patterns of production. Jones and Russell ${ }^{28}$ (1990) discovered that when several evaluation methods occurred simultaneously, typically only one method was optimized. Nelder and Skandalakis ${ }^{42}$ (1999) proposed using benchmarking to diagnose performance in SMEs.

$\mathrm{Kanji}^{30}$ (2002) found that traditional measurement systems focus on short-term results and lack a strategic focus. Chang ${ }^{14}$ (2005) developed a total quality management (TQM) incentive and acknowledgment mechanism. Gieskes, Boer, Baudet, and Seferis ${ }^{21}$ (1999) described a methodology based on continuous improvement by using an ongoing process of evaluation, action, and implementation. Chalmeta and Grangel ${ }^{13}$ (2005) suggested a process for virtual enterprises that compared strategic objectives against a set of indicators.

Barrier $^{4}$ (1994) argued that performance measurements focus on the established goals of the organization and continually evaluate the progress toward meeting them. The maximum impact from performance measurements result from concentrating on ten key areas ("Ten Tips,"48 2004) including use simple flexible measurements and use the results. Busco, Frigo, Giovannoni, Riccaboni, and Scapens ${ }^{10}$ (2006) reported that measuring global operations with multiple locations works by creating a common organizational culture throughout the enterprise.

A PMS survey ("How Companies Utilize,"24 2001) found that the most widely used measurements were sales, revenue, income, margin, earnings, cash flow, and growth. When rating the effectiveness of their PMS slightly more than 33\% thought it was effective, $40 \%$ adequate, and more than $20 \%$ ineffective ("How Companies Utilize," 24 2001). A survey conducted by Morgan $^{39}$ (2000) discovered that about $40 \%$ of the responding organizations had no performance measurement system; another $9 \%$ had a PM system but that it was unsatisfactory; and roughly $60 \%$ had implemented some type of measurement system. Only about $60 \%$ of the respondents were satisfied with their PMS while almost $40 \%$ were unsatisfied $\left(\right.$ Morgan $\left.^{39}, 2000\right)$.

\section{Scope}

The research design utilized for this study (Loendorf $\left.{ }^{33}, 2008\right)$ was an exploratory mixed model design. The study was primarily qualitative with some quantitative aspects resulting in a mixture 
of both models. The quantitative data collected indicated the number of workers, sales percentages, annual sales, and increases or decreases in sales over time. The qualitative data assembled from a set of alternatives to determine how the organization was reacting to global conditions by making changes, using improvement programs, along with entering comments to describe their unique situation and solutions.

The 1,700 members of the National Tooling \& Machining Association (NTMA) represent American tool and die shops of all sizes, ownership types, geographical locations, and financial conditions. As a result, the NTMA has as its membership organizations from all aspects of the American tooling industry. Therefore, the sample selected from their membership directory is representative of all American tool shops. However, many of the tool shops that are on the verge of closing or selling off their assets are not members and thus unavailable for the study. Another unknown is just how much they would contribute, even if selected.

In order to obtain a confidence level of $90 \%$, the calculation according to Creative Research Systems ${ }^{15}$ (2007) and Raosoft ${ }^{45}$ (2007) requires a sample size of 91. An electronic invitation containing a link to the survey was sent to a randomly selected sample of 600 NTMA member organizations. Two follow-up reminder notices were e-mailed to the selected sample one week apart to encourage participation. The response rate approached $16 \%$ with 94 different tool shops returning a completed survey. The number of responses exceeded the 91 required to achieve a confidence level of $90 \%$.

\section{Demographics of Tool Shop Respondents}

Almost $75 \%$ of the 94 responding tool shops employed less than 60 workers while $16 \%$ employed 101 or more workers. Their annual sales were in the 1 to 10 million-dollar range for almost two-thirds of the tool shops. Sales trends over the past three years were mixed with over $35 \%$ of the tool shops decreasing, over $21 \%$ remaining roughly the same, and $43 \%$ with some increase. No international sales were reported by $33 \%$ of the respondents. Another $55 \%$ reported less than one-fifth of their sales were from international sources while none had over $60 \%$ from nondomestic customers. The impact on business from global competition has been negative for almost $94 \%$ of the organizations, no change has been noticed by slightly over $5 \%$, and a minor positive impact was experienced by just over $1 \%$. The overall condition of the responding tool shops business revealed that over $38 \%$ were growing, in excess of $31 \%$ in the stable or steady state mode, while $28 \%$ are contracting. The trends revealed by this data indicate that American tool shops are responding to global competition in different ways with a mixture of results.

\section{Results}

Twenty-five ways to measure performance were selected for this study from focus group input. Table 1 displays the percentage and number of respondents that have considered, planned, or implemented any of the monitoring methods. Multiple selections were allowed and all of the possible PM alternatives were selected numerous times.

The results reveal that a majority of tool shops have already implemented most of these performance-monitoring methods. In fact, almost $69 \%$ of the total selections were made in the implemented column, slightly over $14 \%$ in the planned column, and only $17 \%$ in the considered 
column. This is consistent with reports from Pun and White ${ }^{44}(2005)$ that no one system guarantees success. The three exceptions were number of inventory turns, change in response time, and machine downtime.

Table 1

Performance Measuring Systems Monitoring Operations

\begin{tabular}{|c|c|c|c|}
\hline $\begin{array}{l}\text { Performance monitoring methods } \\
\text { (Number of responses) }\end{array}$ & $\begin{array}{l}\text { Considered } \\
\% \text { (Number) }\end{array}$ & $\begin{array}{l}\text { Planned } \\
\% \text { (Number) }\end{array}$ & $\begin{array}{r}\text { Implemented } \\
\% \text { (Number) }\end{array}$ \\
\hline Change in sales (47) & $10.6(5)$ & $8.5(4)$ & $80.9(38)$ \\
\hline Change in revenue (36) & $11.1(4)$ & $11.1(4)$ & $77.8(28)$ \\
\hline Change in income (34) & $14.7(5)$ & $8.8(3)$ & $76.4(26)$ \\
\hline Change in margin (38) & $15.8(6)$ & $7.9(3)$ & $76.3(29)$ \\
\hline Change in earnings (31) & $16.1(5)$ & $6.5(2)$ & $77.4(24)$ \\
\hline Change in cash flow (40) & $12.5(5)$ & $10.0(4)$ & $77.5(31)$ \\
\hline Change in total expenses (37) & $8.1(3)$ & $10.8(4)$ & $81.1(30)$ \\
\hline Return on investment (27) & $18.5(5)$ & $11.1(3)$ & $70.4(19)$ \\
\hline Organizational growth (28) & $25.0(7)$ & $14.3(4)$ & $60.7(17)$ \\
\hline Number of customers (33) & $21.2(7)$ & $9.0(3)$ & $69.7(23)$ \\
\hline Number of new customers (37) & $13.5(5)$ & $21.6(8)$ & $64.9(24)$ \\
\hline Number of repeat customers (25) & $12.0(3)$ & $12.0(3)$ & $76.0(19)$ \\
\hline Number of new quotes (33) & $24.2(8)$ & $6.1(2)$ & $69.7(23)$ \\
\hline Number of orders won (34) & $20.6(7)$ & $17.6(6)$ & $61.8(21)$ \\
\hline Change in orders shipped (21) & $33.3(7)$ & $4.8(1)$ & $61.9(13)$ \\
\hline Rate of on-time deliveries (41) & $4.9(2)$ & $17.1(7)$ & $78.0(32)$ \\
\hline Change in response time (21) & $23.8(5)$ & $28.6(6)$ & $47.6(10)$ \\
\hline Change in lead time (24) & $25.0(6)$ & $20.8(5)$ & $54.2(13)$ \\
\hline Total time: order to delivery (24) & $25.0(6)$ & $25.0(6)$ & $50.0(12)$ \\
\hline Change in production volume (27) & $18.5(5)$ & $18.5(5)$ & $63.0(17)$ \\
\hline Change in workflow (19) & $15.8(3)$ & $26.3(5)$ & $57.9(11)$ \\
\hline Number of inventory turns (23) & $43.5(10)$ & $8.7(2)$ & $47.8(11)$ \\
\hline Machine downtime (26) & $15.4(4)$ & $38.5(10)$ & $46.2(12)$ \\
\hline Amount of rework/scrap (33) & $9.1(3)$ & $18.2(6)$ & $72.7(24)$ \\
\hline Change in repair costs $(22)$ & $13.6(3)$ & $13.6(3)$ & $72.7(16)$ \\
\hline
\end{tabular}

Note, Respondents could select multiple performance measuring systems.

The performance monitoring methods receiving the highest number of responses were change in sales, rate of on-time deliveries, change in cash flow, change in margin, and a tie between change in total expenses and number of new customers. Five of these six indicate a financial emphasis while the other two target customer satisfaction. The performance measuring techniques with the lowest number of selections were change in workflow, change in response time, change in orders shipped, change in repair costs, and number of inventory turns. Although two of these are related to financial considerations, overall they indicate non-financial measures. 
The most frequently implemented performance measurement systems by percentage were change in total expenses, change in sales, rate of on-time deliveries, change in revenue, change in cash flow, and change in earnings. When examined in terms of the total number of selections the order becomes change in sales, rate of on-time deliveries, change in cash flow, change in total expenses, and change in revenue. These selections reveal the significance of monitoring the financial aspects of the business while controlling expenses and checking for sales trends. Of the top ten selections, only two by percentage and three by total number of selections were not related to some financial measure. However, these were associated with obtaining new customers and satisfying the current customers.

When it came to performance measures that were planned, the most frequent selections by percentage were machine downtime, change in response time, change in workflow, total time: order to delivery, and number of new customers. When the total number of selections are considered the order changes to machine downtime, number of new customers, rate of on-time deliveries, number of orders won, amount of rework/scrap, and total time: order to delivery. These aspects of the business point toward an emphasis on obtaining new business and streamlining operations in order to improve performance. In every case, the percentages for planned performance measuring systems were significantly lower than those for already implemented monitoring methods.

For those systems being considered, the top choices were number of inventory turns, change in orders shipped, organizational growth, change in lead-time, and total time: order to delivery. When viewed by the total number of selections the ranking shifts to number of inventory turns, number of new quotes, number of orders won, number of customers, organizational growth, and change in orders shipped. The competitive nature of the business is evident with these selections for improving efficiency and streamlining operations. Also reflected in the results is the importance of monitoring the organization's health.

Implementing performance measuring systems is only one aspect while determining the frequency of their computation and use is another. It takes resources in terms of time, personnel, and capital to constantly monitor, calculate, and analyze performance. Ideally, it would be nice to utilize this data instantaneously for an up to the minute report on operations. However, this is simply not feasible.

Table 2 displays just how frequently the tool shops are monitoring their performance. The results indicate a strong tendency by the number of selections toward a monthly or weekly assessment in contrast to a quarterly, daily, or annual evaluation. This suggests a compromise between the need to monitor performance and its overhead cost.

A relatively low number $(11 \%)$ of tool shops do a daily evaluation of their performance. The top selections for daily review by percentage were change in workflow, amount of rework/scrap, change in cash flow, machine downtime, and total time: order to delivery. Four of these monitor some facet of the production process while the fifth is a critical financial characteristic. The top two by number of selections are change in cash flow and amount of rework/scrap. Overall these selections stress the importance of closely examining and controlling the production and financial aspects of the business. 
Table 2

Frequency of Use of the Performance Measuring Systems

\begin{tabular}{|c|c|c|c|c|c|}
\hline $\begin{array}{l}\text { Performance monitoring methods } \\
\text { (Number of responses) }\end{array}$ & $\begin{array}{l}\text { Daily } \\
\%(\#)\end{array}$ & $\begin{array}{l}\text { Weekly } \\
\%(\#)\end{array}$ & $\begin{array}{l}\text { Monthly } \\
\%(\#)\end{array}$ & $\begin{array}{l}\text { Quarterly } \\
\text { \% (\#) }\end{array}$ & $\begin{array}{l}\text { Annually } \\
\%(\#)\end{array}$ \\
\hline Change in sales (40) & $10.0(4)$ & $32.5(13)$ & $40.0(16)$ & $12.5(5)$ & $5.0(2)$ \\
\hline Change in revenue (30) & $6.7(2)$ & $20.0(6)$ & $50.0(15)$ & $20.0(6)$ & $3.3(1)$ \\
\hline Change in income (28) & $10.7(3)$ & $14.3(4)$ & $60.7(17)$ & $14.3(4)$ & $0.0(0)$ \\
\hline Change in margin (29) & $13.8(4)$ & $13.8(4)$ & $58.6(17)$ & $13.8(4)$ & $0.0(0)$ \\
\hline Change in earnings (24) & $8.3(2)$ & $12.5(3)$ & $62.5(15)$ & $16.7(4)$ & $0.0(0)$ \\
\hline Change in cash flow (31) & $22.6(7)$ & $38.7(12)$ & $32.3(10)$ & $3.2(1)$ & $3.2(1)$ \\
\hline Change in total expenses (29) & $13.8(4)$ & $6.9(2)$ & $62.1(18)$ & $10.3(3)$ & $6.9(2)$ \\
\hline Return on investment (21) & $0.0(0)$ & $4.8(1)$ & $33.3(7)$ & $23.8(5)$ & $38.1(8)$ \\
\hline Organizational growth (18) & $11.1(2)$ & $5.6(1)$ & $38.9(7)$ & $16.7(3)$ & $27.8(5)$ \\
\hline Number of customers (24) & $4.2(1)$ & $33.3(8)$ & $29.2(7)$ & $20.8(5)$ & $12.5(3)$ \\
\hline Number of new customers (26) & $11.5(3)$ & $38.5(10)$ & $26.9(7)$ & $15.4(4)$ & $7.7(2)$ \\
\hline Number of repeat customers (19) & $0.0(0)$ & $52.6(10)$ & $31.6(6)$ & $10.5(2)$ & $5.3(1)$ \\
\hline Number of new quotes (24) & $4.2(1)$ & $54.2(13)$ & $37.5(9)$ & $4.2(1)$ & $0.0(0)$ \\
\hline Number of orders won (22) & $0.0(0)$ & $36.4(8)$ & $59.1(13)$ & $4.5(1)$ & $0.0(0)$ \\
\hline Change in orders shipped (14) & $7.1(1)$ & $42.9(6)$ & $42.9(6)$ & $0.0(0)$ & $7.1(1)$ \\
\hline Rate of on-time deliveries (30) & $6.7(2)$ & $20.0(6)$ & $53.3(16)$ & $16.7(5)$ & $3.3(1)$ \\
\hline Change in response time (13) & $15.4(2)$ & $53.8(7)$ & $23.1(3)$ & $7.7(1)$ & $0.0(0)$ \\
\hline Change in lead-time (15) & $6.7(1)$ & $46.7(7)$ & $33.3(5)$ & $13.3(2)$ & $0.0(0)$ \\
\hline Total time: order to delivery (15) & $20.0(3)$ & $20.0(3)$ & $40.0(6)$ & $6.7(1)$ & $13.3(2)$ \\
\hline Change in production volume (19) & $10.5(2)$ & $31.6(6)$ & $42.1(8)$ & $15.8(3)$ & $0.0(0)$ \\
\hline Change in workflow (11) & $27.3(3)$ & $45.5(5)$ & $18.2(2)$ & $9.1(1)$ & $0.0(0)$ \\
\hline Number of inventory turns (14) & $14.3(2)$ & $7.1(1)$ & $42.9(6)$ & $0.0(0)$ & $35.7(5)$ \\
\hline Machine downtime (15) & $20.0(3)$ & $26.7(4)$ & $40.0(6)$ & $13.3(2)$ & $0.0(0)$ \\
\hline Amount of rework/scrap (26) & $23.1(6)$ & $19.2(5)$ & $50.0(13)$ & $7.7(2)$ & $0.0(0)$ \\
\hline Change in repair costs (16) & $18.8(3)$ & $0.0(0)$ & $75.0(12)$ & $6.3(1)$ & $0.0(0)$ \\
\hline Number of Selections (553) & 61 & 145 & 247 & 66 & 34 \\
\hline Percentage of Selections & 11.0 & 26.2 & 44.7 & 11.9 & 6.1 \\
\hline
\end{tabular}

Note, Respondents could select multiple performance measuring systems.

Over a quarter of the performance appraisals, were performed on a weekly basis. The top performance measuring systems by percentage were number of new quotes, change in response time, number of repeat customers, change in lead-time, and change in workflow. The ranking by number of selections becomes change in sales, number of new quotes, change in cash flow, number of new customers, and number of repeat customers. These business aspects can be viewed first as critical sales parameters and second as manufacturing issues that require frequent analysis. 
Most of the performance measuring systems (almost 45\%) were utilized on a monthly basis. The top nine choices were selected by more than $50 \%$ of the respondents. The leading choices by percentages were change in repair costs, change in earnings, change in total expenses, change in income, and number of orders won. The top five by number of selections are change in total expenses, change in margin, change in income, change in sales, and rate of on-time deliveries. These suggest the vital importance of financial figures to tool shops along with the need for them to make a consistent profit. These also highlight a strong emphasis on monitoring production and machinery problems.

The review of performance on a quarterly basis was done by approximately $12 \%$ of the tool shops. The most frequently selected methods by percentage were return on investment, number of customers, change in revenue, change in earnings, and organizational growth. Looking at the number of selections yields a slightly different order: change in revenue, change in sales, rate of on-time deliveries, number of customers, and return on investment. However, the percentages for all of the selections and the total number of selections in this timeframe were low indicating the time interval was too far apart to effectively recognize problems and react.

The lowest percentage of respondents (just over 6\%) reviewed their operations on an annual basis. Only return on investment had the highest percentage of use annually over the other timeframes for review. More top choices by percentage were number of inventory turns, organizational growth, total time: order to delivery, and number of customers. The top three by number of selections were return on investment, organizational growth, and number of inventory turns. In this category 12 of the performance measuring systems were not even selected, five were picked only once, and another four were chosen only twice. However, the top selections reflect the significance of profits, growth, and utilization of resources; information that is usually included in annual reports.

The respondents had the opportunity to comment on or suggest additional ways that they were using to judge the tool shops performance. First additional measurements along with their timeframe are presented followed by some pertinent comments.

1. Reduction in paperwork - planning to implement.

2. Annual sales per employee - measured quarterly.

3. Bookings - measured monthly.

4. Sales per employee - measured monthly.

5. Safety - measured monthly.

6. Days sales outstanding - measured monthly.

7. Non-chargeable time - measured monthly.

8. Planning to implement many of these while others are all in process now with regular report cards or other evaluation methods being put in place.

9. While it is good to measure these items, when the volume drops dramatically it is difficult to change the impact. Therefore, measuring it does not do much good.

Interest was noted in measuring: the reduction of paperwork, sales per employee, sales bookings, days sales outstanding, non-chargeable time, and safety issues. Only the sales per employee were mentioned more than once with either a monthly or quarterly review. Worker safety is always of critical importance in a manufacturing environment but only stated as a performance 
measurement by one tool shop. Unfortunately, if rapid and drastic negative changes occur none of the monitoring methods may reflect the impact in required time to counteract their effect.

Table 3 shows the respondent's confidence in the accuracy of the performance monitoring data. Three areas of confidence were actually evaluated simultaneously: the acceptance of the data, testing of the measurements, and the accuracy of the data. The respondents could select multiple answers but only a few (14) actually did. This indicates that the confidence in the performance data collected was adequately represented by primarily one selection. However, the best way to analyze the results is to break Table 3 into three groups each containing three rows working from the top down.

Table 3

Confidence in Accuracy of Performance Monitoring Data

\begin{tabular}{lc}
\hline Confidence in performance data & $\%$ (Number) \\
The accuracy is never questioned or critiqued. & $4.6(5)$ \\
Nothing is ever done to test the accuracy. & $3.7(4)$ \\
The same methods have always worked successfully in the past. & $10.2(11)$ \\
The accuracy of the measurements are rarely tested. & $8.3(9)$ \\
The accuracy of the measurements are periodically tested. & $21.3(23)$ \\
The accuracy of the measurements are frequently tested. & $11.1(12)$ \\
Very confident that the methods used are accurate. & $19.4(21)$ \\
Somewhat confident that the methods used are accurate. & $18.5(20)$ \\
Not very confident that the methods used are accurate. & $2.8(3)$
\end{tabular}

Note, Respondents could select multiple confidence levels.

First, over $10 \%$ of the respondents indicated that the same methods have always worked successfully in the past, for almost $5 \%$ the accuracy is never questioned or critiqued, and approximately $4 \%$ noted that nothing is ever done to test the accuracy. This means that over $18 \%$ of the tool shops that answered this subset of questions simply do not question the accuracy of their performance data. Second, the accuracy of the measurements was rarely tested by slightly over $8 \%$, periodically tested by $21 \%$, and frequently tested by $11 \%$ of the tool shops. This indicates that 35 out of the 44 tool shops answering this subset of questions or $80 \%$ do some level of accuracy testing of their performance data. Third, just over $19 \%$ of the tool shops were very confident, over $18 \%$ somewhat confident, and almost $3 \%$ not very confident that the methods used are accurate. Reviewing this data in a different way, 41 out of the 44 respondents to this subset of questions or $93 \%$ had some degree of confidence in the data.

The respondents were given the opportunity to comment, offer input on the accuracy of the data collected, and relate the confidence they have in their collected performance data. The comments state:

1. We are capturing very accurate data for everything we do.

2. We use video, job costing records, and estimates to critique our measurement data.

3. We continue to improve our methods, but human error is still a factor. 
4. Lack of funds is a critical factor when reviewing performance data.

5. We have an annual review done by our CPA for accounting number accuracy.

These comments stress the capturing of very accurate data along with the effects of human error. Methods using video surveillance, job costing, and using estimates were suggested. In one case, they are trying to improve but lack of funds hinders the effort. In another case, a CPA annually reviews all financial data and this is probably true for other tool shops that took it for granted and did not mention it specifically.

Collecting performance monitoring data is one thing, how that data is used is another far more important consideration. Sixteen possible uses for the data were selected for this study. Table 4 shows exactly how the tool shops utilize their performance data and multiple selections were allowed. The data included in the Table can be interpreted best by looking at the top six rows first. Reviewing the first three rows shows that only two respondents stated that no performance data is collected. Another two noted that data is collected but never used and four declared that the data is used only for report writing purposes.

Table 4

Use of the Data Collected by Performance Measurements

\begin{tabular}{lr}
\hline \multicolumn{1}{c}{ Usage of performance data } & \% (Number) \\
No performance measurement data is collected. & $0.7(2)$ \\
Data is collected but never utilized. & $0.7(2)$ \\
Data is used only for report writing purposes. & $1.3(4)$ \\
Data is reviewed but no actions are taken. & $0.3(1)$ \\
Data is reviewed but rarely leads to corrective action. & $6.0(18)$ \\
Data is reviewed and always leads to renewed action plans. & $7.0(21)$ \\
Data is used to critique the organizations operation. & $11.3(34)$ \\
Data is used to critique between desired and actual results. & $8.9(27)$ \\
Data is used to determine the root cause of deficiencies. & $8.3(25)$ \\
Data is used to determine where corrective actions are needed. & $10.9(33)$ \\
Data is used to determine if improvement programs work. & $8.3(25)$ \\
Data is used to select new improvement programs. & $6.0(18)$ \\
Data is used as a catalyst for updating/streamlining operations. & $6.6(20)$ \\
Data is used as a catalyst for improving the products quality. & $7.3(22)$ \\
Data is used as a catalyst for improving efficiency. & $8.9(27)$ \\
Data is used to establish priorities for improvement projects. & $7.6(23)$ \\
\end{tabular}

Note, Respondents could select multiple uses for performance data.

Data from rows four through six of Table 4 reveals changes resulting from the performance data. Only one respondent out of the 40 answered: data is reviewed but no actions are taken. Another 18 out of 40 responses indicated that: data is reviewed but rarely leads to corrective action. On the other hand 21 out of the 40 respondents to this set of questions declared: data is reviewed and always leads to renewed action plans. 
The top three responses from Table 4 were data is used to critique the organizations operation, data is used to determine where corrective actions are needed, and data is used to critique between desired and actual results. These were followed by data is used as a catalyst for improving efficiency, data is used to determine if improvement programs work, and data is used to determine the root cause of deficiencies. These selections indicate that the data is being used in a constructive way to improve performance by over $56 \%$ of the responding tool shops. This suggests that a majority of the tool shops are utilizing the performance data exactly as intended. However, this also means that other tool shops are not using it.

The respondents also provided further insight into the use of performance measurement data through their comments:

1. Going to start using the data.

2. Many of the items are used and monitored as required.

3. Our customers have forced us to perform.

4. If we don't perform, we lose a customer.

5. You better be looking for ways to improve every day.

6. Always looking for ways to improve service to our customers and help the bottom line.

The comments reflect on starting to use the data and monitoring as required. Others stated they have been forced to perform or else the customers would take their business elsewhere. Perhaps the best summarizing comment was the importance of always looking for ways to improve. These comments also demonstrate the varied use of performance data. Starting with no use yet, moving on to being forced to use it by their customers, and finally almost to a threat that you had better improve or else.

A variety of performance monitoring techniques are being used by the American tooling industry. This is consistent with reports from Pun and White ${ }^{44}$ (2005). Each tool shop uses a number of them to measure and analyze the financial and non-financial aspects of their business. Exactly which ones are used differ from one tool shop to the next. This is consistent with and reinforces why there are so many ways to measure performance as presented in the literature review. Most utilized on a monthly or weekly basis with their accuracy typically accepted, even though in many cases without proof.

\section{Implementation}

Many engineers, at some point in their career, will become managers. Most engineering managers focus on product development, materials management, production processes, and workforce reliability. Management engineers apply engineering principles to the planning and operational management of industrial and manufacturing operations. Engineering managers combine management expertise with engineering knowledge to lead teams, departments, and companies in highly technical tasks.

The Department of Engineering \& Design offers degrees in Electrical Engineering, Computer and Mechanical Engineering Technology, Design, Manufacturing, Applied Technology, and Construction Management. The primary goal is to provide students with the technical 
background required for successful careers in industry and business. The coursework within each program offers opportunities and experiences in real-world situations that enhance the preparation of graduates.

Results from this study have already been incorporated into courses that include: Problem Analysis and Design; Machine Tool; Computer-Aided Design; Project Management; Quality Assurance; Engineering Economics; Environmental Engineering; Engineering Ethics, Contracts, and Patents; Industrial Safety Engineering; Computing Systems; and Technology in World Civilization. These courses offer real-world exposure to the field of engineering management along with the skills necessary for graduates to be successful in their chosen career field. The material derived from this study has also been successfully utilized in the Senior Engineering Capstone, Senior Capstone: Production Laboratory, and Senior Project courses, along with the Industrial Internship Program.

This integration has occurred in various components of these courses. The textbook readings, lectures, and discussions were revised in order to emphasize the findings from the study. In addition homework assignments, case studies, and real world experiences derived from the study were included as individual or group exercises.

Homework assignments and case studies related to performance measurements were developed and implemented for the aforementioned senior courses. In each case, the students are to apply their knowledge of performance monitoring techniques to the particular problem and analyze their effectiveness, suggest improvements, and then implement them. In addition, various exercises and case studies were developed from the study's findings specifically for use as an integral part of the lecture and discussion aspects of the courses.

A slightly different approach was used to apply the knowledge obtained from this study in the Industrial Internship Program. In this case, the students are asked to examine and critique the performance monitoring methods currently in use by their employer. Then analyze their effectiveness, recommend improvements, and if possible implement them. A final report is required that reviews the effectiveness of the improvements made in comparison to what was previously used. This real-world application has proven to be particularly useful to the student's employers resulting in numerous letters and emails supporting the Internship Program.

These assignments and case studies add a real-world component to the study of performance monitoring techniques. By studying actual events, the students become better prepared for the challenges they will face during their professional careers. This, in turn, makes them more valuable as an engineer and manager to their employer.

\section{Conclusions}

The types of performance monitoring techniques utilized as well as the frequency of their use varied (Table 1). The responding tool shops made 761 selections from the 25 possible systems. The number of programs selected by each tool shop ranged from a low of four to a high of ten. Four of the top six techniques with the highest number of selections were of a financial nature while the other two related to customers. They included change in sales, rate of on-time 
deliveries, change in cash flow, change in margin, change in total expenses, and number of new customers. Twenty-two of the 25 performance monitoring systems have already been implemented by $50 \%$ or more of the tool shops. This reflects the importance placed on measuring performance by the tool shops. When evaluated by percentages, change in total expenses and change in total sales were already implemented by over $80 \%$ of the organizations. In every case, the already implemented percentages exceeded the percentages for planned and considered. The measurement systems planned focused on streamlining operations to improve performance while those considered concentrated on maintaining sales volumes, improving efficiency, and obtaining new business. These choices clearly reveal the importance of monitoring financial data, customer satisfaction, as well as production efficiency. Since tool shops are predominately small businesses these aspects are crucial for their survival.

The frequency of use for these performance monitoring practices varied (Table 2). Almost $45 \%$ of the tool shops use a monthly timeframe while over $26 \%$ review them on a weekly basis. Evaluation of some very critical aspects of the business on a daily basis occurred including changes in workflow, cash flow, rework/scrap, machine downtime, and total time: order to delivery. Quarterly reviews included return on investment, number of customers, and change in revenue. Only about half of the items were reviewed on an annual basis. The results show the significance of monitoring performance on a weekly or monthly timeframe to insure that conditions do not get out of control; when they do corrective actions can be quickly started. Closely monitoring financial and production data catches trends in their early stages to accentuate the positive ones and minimize the negative ones.

The levels of confidence in the accuracy of the performance measuring data also varied (Table 3). The number of responses received was 108 indicating that a few tool shops selected more than one answer. Over $10 \%$ reported that the same methods have always worked successfully in the past while almost $5 \%$ said the accuracy was never questioned or critiqued. However, the accuracy of the measurements was tested by about one-third of the responding tool shops. Almost $38 \%$ of the respondents were confident to some degree that the results were accurate. Clearly more testing could check the accuracy of the performance measurements made. However, inadequate resources likely limit and promote the lack of further testing.

The data collected by performance monitoring systems was used for a variety of purposes (Table 4). Considering the 16 possible uses for the data, the respondents made 302 selections. The number of uses selected by each tool shop ranged from a low of one to a high of six. The highest number of selections indicate the data was used to critique the organizations operation as well as determine where corrective actions were needed. Over $91 \%$ of the respondents used the data to improve the organizations performance in some way. Unfortunately, that leaves $9 \%$ of the tool shops that did little or nothing with the data.

When all of these conclusions are combined it is noted that performance measures (of a wide variety) are being used by the American tooling industry (in some but not all shops) to demonstrate the improvement programs (to a varying level or degree) have made a measurable competitive difference (even though the accuracy of the measure may not be checked). Predominantly the data used had a financial and manufacturing nature. However, the data 
collected was not always used to analyze and improve performance. In addition, the accuracy of the collected data was frequently not questioned, but accepted as fact.

The results from this study into performance monitoring methods are of paramount importance to local tool and die shops as well as the entire American tooling industry. It is also vital that educational institutions incorporate performance monitoring techniques, processes, and procedures into the engineering management portion of the engineering and engineering technology curriculum. This has been accomplished by integrating the results derived from this study into a number of core program courses. The intent is to better prepare graduates for careers in engineering management for manufacturing related engineering positions while helping their employers regain or maintain their ability to compete.

\section{Bibliography}

1. Atkinson, A. (2000). Measure for measure. CMA Management, 74(7), 22-28.

2. Bailey, L. (2003). Where can you improve? Get the numbers. Crain's Detroit Business, 19(3), 14-17.

3. Berg, D. M. (1998). Retooling for a globalized market: Adaptation in the United States machine tool industry. Dissertation Abstracts International, 59(02), 547. (AAT 9823805)

4. Barrier, M. (1994). Learning the meaning of measurement. Nation's Business, 82(6), 72-75.

5. Bento, A. M., \& White, L. F. (2001). Organizational form, performance and information costs in small businesses. Journal of Applied Business Research, 17(4), 41-61.

6. Berrah, L., Mauris, G., \& Vernadat, F. (2004). Information aggregation in industrial performance measurement: Rationales, issues and definitions. International Journal of Production Research, 42(20), 4271-4293.

7. Bititci, U. S., Turner, T., \& Begemann, C. (2000). Dynamics of performance measurement systems. International Journal of Operations and Production Management, 20(6), 692-704.

8. Bourne, M. (2005). Researching performance measurement system implementation: The dynamics of success and failure. Production Planning \& Control, 16(2), 101-113.

9. Bryant, L., Jones, D. A., \& Widener, S. K. (2004). Managing value creation within the firm: An examination of multiple performance measures. Journal of Management Accounting Research, 16, 107-131.

10. Busco, C., Frigo, M. L., Giovannoni, E., Riccaboni A., \& Scapens, R. W. (2006). Integrating global organizations through performance measurement systems. Strategic Finance, 87(7), 31-35.

11. Castellano, J. F., \& Young, S. (2006). Changing your performance measurement mindset: The key to improved decision making. CMA Management, 80(3), 26-31.

12. Castellano, J. F., Young, S., \& Roehm, H. A. (2004). The seven fatal flaws of performance management. CPA Journal, 74(6), 32-35.

13. Chalmeta, R., \& Grangel, R. (2005). Performance measurement systems for virtual enterprise integration. International Journal of Computer Integrated manufacturing, 18(1), 73-84.

14. Chang, H. H. (2005). The influence of continuous improvement and performance factors in total quality organization. Total Quality Management \& Business Excellence, 16(3), 413-437.

15. Creative Research Systems (2007). Sample size calculating software [Computer program]. Retrieved from http://www.surveysystem.com/sscalc.htm

16. Deming, W. E. (1982). Quality, productivity, and competitive position. Cambridge, MA: Massachusetts Institute of Technology.

17. Dervitsiotis, K. N. (2004). The design of performance measurement systems for management learning. Total Quality Management \& Business Excellence, 15(4), 457-473.

18. Franco-Santos, M., \& Bourne, M. (2005). An examination of the literature relating to issues affecting how companies manage through measures. Production Planning \& Control, 16(2), 114-124.

19. Frigo, M. L. (2002). Strategy focused performance measures. Strategic Finance, 84(3), 10-13.

20. Garengo, P., Biazzo, S., \& Bititci, U. S. (2005). Performance measurement systems in SMEs: A review for a research agenda. International Journal of Management Reviews, 7(1), 25-47. 
21. Gieskes, J. F. B., Boer, H., Baudet, F. C. M., \& Seferis, K. (1999). CI and performance: A CUTE approach. International Journal of Operations \& Production Management, 19(11), 1120-1137.

22. Gough, K. (2003). Performance measurement in the supply chain. Logistics \& Transport Focus, 5(5), 78-79.

23. Gregory, E., \& Myers, R. (2002). Help clients take measure. Journal of Accountancy, 193(6), 53-58.

24. How companies utilize performance measurement systems (2001, June). IOMA's Report on Managing the General Ledger, 1(6), 11-14.

25. Hudson, M., Lean, J., \& Smart, P. A. (2001). Improving control through effective performance measurement in SMEs. Production Planning \& Control, 12(8), 804-813.

26. Hudson, M., Smart, A., \& Bourne, M. (2001). Theory and practice in SME performance measurement systems. International Journal of Operations and Production Management, 21(8), 1096-1115.

27. Hvolby, H. H., \& Thorstenson, A. (2001). Indicators for performance measurement in small and medium-sized enterprises. Proceedings of the Institution of Mechanical Engineers - Part B - Engineering Manufacture, 215(8), 1143-1146.

28. Jones, M. S., \& Russell, R. S. (1990). Multiple performance measures in the selection of a sequencing rule. International Journal of Operations \& Production Management, 10(8), 29-41.

29. Kanji, G. K. (1998). Measurement of business excellence. Total Quality Management, 9(7), 633-643.

30. Kanji, G. K. (2002). Performance measurement system. Total Quality Management, 13(5), 715-728.

31. Kaplan, R. S., \& Norton, D. P. (1992). The balanced scorecard: Measures that drive performance. Harvard Business Review, 70(1), January-February, 71-79.

32. Lockamy, A. (1998). Quality focused performance measurement systems: A normative model. International Journal of Operations and Production Management, 18(8), 740-766.

33. Loendorf, W. R. (2008). Transition of the tooling industry in a competitive global environment. Dissertation Abstracts International, 69(03). (AAT 3297978)

34. Lyles, M. A., Baird, I. S., Orris, J. B., \& Kuratko, D. F. (1993). Formalized planning in small business: Increasing strategic choices. Journal of Small Business Management, 31(2), 38-50.

35. Medori, D., \& Steeple, D. (2000). A framework for auditing and enhancing performance management systems. International Journal of Operations and Production Management, 20(5), 520-533.

36. Mendibil, K., \& MacBryde, J. (2005). Designing effective team-based performance measurement systems: An integrated approach. Production Planning \& Control, 16(2), 208-225.

37. Micheli, P., \& Kennerly, M. (2005). Performance measurement frameworks in public and non-profit sectors. Production Planning \& Control, 16(2), 125-134.

38. Morgan, C. (2003). Measuring performance: Supply chain challenge. Logistics \& Transport Focus, 5(2), 44-46.

39. Morgan, J. (2000). How effective are your measurement systems. Purchasing, 129(10), 26-29.

40. Neely, A., \& Al Najjar, M. (2006). Management learning not management control: The true role of performance management. California Management Review, 48(3), 99-114.

41. Neely, A., Mills, J., Platts, K., Richards, H., Gregory, M., Bourne, M., \& Kennerley, M. (2000). Performance measurement system design: Developing and testing a process based approach. International Journal of Operations \& Production Management, 20(9/10), 1119-1145.

42. Nelder, G. P., \& Skandalakis, A. (1999). Diagnostic benchmarking for small- and medium-sized enterprises. Proceedings of the Institution of Mechanical Engineers - Part B Engineering Manufacture, 213(3), 323-327.

43. Nudurupati, S. S., \& Bititci, U. S. (2005). Implementation and impact of IT supported performance measurement systems. Production Planning \& Control, 16(2), 152-162.

44. Pun, K. F., \& White, A. S. (2005). A performance measurement paradigm for integrating strategy formulation: A review of systems and frameworks. International Journal of Management Reviews, 7(1), 49-71.

45. Raosoft (2007). Sample size calculating software [Computer program]. Retrieved from http://www.raosoft.com/samplesize.html

46. Riggs, J. L. (1983). Productivity by objectives. New York: Prentice Hall.

47. Tae-Eog, L., \& Posner, M. E. (1997). Performance measures and schedules in periodic job shops. Operations Research, 45(1), 72-91.

48. Ten tips for maximizing impact of measurement (2004, December). Financial Executive, 20(9), 11-12.

49. Waggoner, D. B., Neely, A. D., \& Kennerley, M. P. (1999). The forces that shape organisational performance measurement systems: An interdisciplinary review. International Journal of Production Economics, 60/61(3), 53-60.

50. Wouters, M., \& Sportel, M. (2005). The role of existing measures in developing and implementing performance measurement systems. International Journal of Operations \& Production Management, 25(11), 1062-1082. 